\title{
Estimating velocity from noisy GPS data for investigating the temporal variability of slope movements
}

\author{
V. Wirz ${ }^{1}$, J. Beutel ${ }^{2}$, S. Gruber ${ }^{3}$, S. Gubler ${ }^{4}$, and R. S. Purves ${ }^{1}$ \\ ${ }^{1}$ Department of Geography, University of Zurich, Switzerland \\ ${ }^{2}$ Computer Engineering and Networks Laboratory, ETH, Zurich, Switzerland \\ ${ }^{3}$ Carleton University, Ottawa, Canada \\ ${ }^{4}$ Federal office of Meteorology and Climatology Meteoswiss, Zurich, Switzerland \\ Correspondence to: V. Wirz (vanessa.wirz@geo.uzh.ch)
}

Received: 10 January 2014 - Published in Nat. Hazards Earth Syst. Sci. Discuss.: 5 February 2014

Revised: - - Accepted: 22 July 2014 - Published: 23 September 2014

\begin{abstract}
Detecting and monitoring of moving and potentially hazardous slopes requires reliable estimations of velocities. Separating any movement signal from measurement noise is crucial for understanding the temporal variability of slope movements and detecting changes in the movement regime, which may be important indicators of the process. Thus, methods capable of estimating velocity and its changes reliably are required. In this paper we develop and test a method for deriving velocities based on noisy GPS (Global Positioning System) data, suitable for various movement patterns and variable signal-to-noise-ratios (SNR). We tested this method on synthetic data, designed to mimic the characteristics of diverse processes, but where we have full knowledge of the underlying velocity patterns, before applying it to explore data collected.
\end{abstract}

\section{Introduction}

Slope movement and the development of related instabilities are both natural mass-transfer processes and bring potential risks to infrastructure and human life. Investigating and understanding processes governing slope movement is key to the development of risk reduction frameworks which seek to provide early warning of significant slope movements. In particular, changes in slope velocity can be indicators of not only developing instabilities, but also related processes such as snowmelt infiltration or changes in ground temperature.

The importance of improved understanding of such processes, particularly in periglacial regions, is emphasized by predicted and observed changes to slope stability, which are postulated to be related to permafrost thaw and glacier retreat (Haeberli et al., 1997).

A number of observations of rapid mass movements have been made in periglacial regions (e.g. Lewkowicz and Harris, 2005) and, additionally, pronounced accelerations of rock glaciers in Europe have been observed (e.g. Roer et al., 2008; Delaloye et al., 2008b), and hypothesized to be driven by increasing air temperatures (e.g. Delaloye et al., 2010). However, due to difficult access, slopes in steep mountain terrain are challenging to monitor, and often observations take the form of repeated manual campaigns during the snow-free period. These only allow measurement of interannual (Lambiel and Delaloye, 2004) or, if repeated a few times per year, coarse seasonal variations in velocity (e.g. Perruchoud and Delaloye, 2007). To analyse short-term velocity fluctuations, higher temporal resolution is required. As many slopes have low rates of displacement (a few $\mathrm{cm}$ per year), very accurate measurements and effective methods for their interpretation are required to observe such behaviour.

Observing surface displacement is a cost-effective method for investigating the dynamics of unstable slopes. In principle, any approach which allows repeated measurements of known points can provide insights into surface movements. Where the aim is to measure very small displacements over a long time period, continuous in situ observations have proved effective. Of these, GPS (Global Positing System, or other Global Navigation Satellite Systems) has proved to be particularly suitable and has been widely applied to study landslides (e.g. Gili et al., 2000; Malet et al., 2002; 
Coe et al., 2003; Squarzoni et al., 2005) and rock glaciers (e.g. Lambiel and Delaloye, 2004; Delaloye et al., 2008a). Its advantages include (a) the possibility to measure in three dimensions (3-D) with millimetre accuracy (Limpach and Grimm, 2009) and high temporal resolution, (b) relative independence from weather conditions (note that high winds may however cause mast displacements, and snow coverage signal loss), (c) no requirement for direct visibility between measurement points, and (d) autonomous operation (Malet et al., 2002).

Essentially, GPS measurements of slopes generate time series of positions, from which a wide variety of movement parameters (MPs) such as speed, direction or acceleration can be derived. All MPs must be estimated using a set of positions, and are thus strongly dependent on the selected time window (number of measurement points; Laube and Purves, 2011; Jerde and Visscher, 2005; Berthling et al., 2000). The limiting factor in estimating temporal variation in a MP is the precision and accuracy of the positional measurements themselves. Thus, a MP can only be estimated meaningfully where there is sufficient movement between consecutive estimates of MPs (Jerde and Visscher, 2005) since data with a low signal-to-noise ratio (SNR) cannot support reliable estimates (Laube and Purves, 2011). For example, GPS measurements of slope displacements with high temporal resolutions (e.g. daily) typically have a low SNR (Massey et al., 2013) due to their low velocities. Even for GPS measurements on glaciers with comparably higher velocities, a low SNR was reported (Dunse et al., 2012; Vieli et al., 2004). The estimation of MPs from noisy position data typically involve the fitting of some function to the data. The simplest possibility is to fit a linear regression to a set of points, with common methods including the use of splines (e.g. Copland et al., 2003; Hanson and Hooke, 1994) or a smoothing over several days (e.g. Dunse et al., 2012). However, these approaches assume a continuous SNR over the entire time series. While some movements might show a steady displacement, others have strong short-term variability and thus a highly variable SNR (glaciers: e.g. Vieli et al., 2004 and Dunse et al., 2012; landslides: Coe et al., 2003; and permafrost slopes: Buchli et al., 2013). Additionally, the noise level of GPS-derived positions is variable in time, further contributing to temporally variable SNR in data collected using such methods. A key requirement in studying short-term variability of slope movements based on continuous GPS is thus a method which can estimate signal and noise and adapt time windows locally. Such an approach will ensure that large displacements are not oversmoothed, while a displacement signal is only detected where it actually exists. One candidate method is kernel regression smoothing (KRS) using local bandwidths (smoothing windows) optimized based on the noise level of the data (Herrmann, 1997). However, experiences have shown that KRS using local bandwidths tends to overestimate the variability of the data (M. Mächler, personal communication, 2013).
Our study has the following aims: (a) developing and testing a robust method for analysing movement data with low and variable SNR. (b) A comparison of the developed method to existing approaches assuming (i) a constant sampling window and (ii) local bandwidths. (c) Illustrating the application of the new method to a case study.

The proposed method is called SNRT (signal-to-noise thresholding). It uses Monte Carlo simulations to estimate the uncertainty in individual positions and thus to derive a SNR and, iteratively, an appropriate sampling window. It thus differs from KRS in that derived MPs are not, per se, smoothed. To allow comparison of the method we firstly generated synthetic time series, before exploring the results obtained from two 1-year time series of daily GPS measurements with subcentimetre accuracy. Both stations are located on the orographic right side of the Matter Valley, Switzerland: one on a fast rock glacier, the other one on a large and deep-seated complex landslide. Both locations are situated in permafrost and thus relevant to the understanding of cryosphere-moderated-temperature control of slope movements and associated natural hazards.

\section{Study area}

The study site is located above the villages Herbriggen and Randa at the orographic right side of the Mattertal, in the Canton of Valais, Switzerland. The two GPS stations are located on west-facing slopes of the peak Breithorn ( $3178 \mathrm{~m}$ a.s.l. - above sea level) with a mean slope angle of approximately $30^{\circ}$. Permafrost is abundant in this area (Boeckli et al., 2012). The main lithology is gneiss belonging to the crystalline Mischabel unit (Labhart, 1995). In most places the bedrock is covered with debris, either originating from weathering of the bedrock or from various gravitational processes such as rockslides. At most places vegetation is rare. Station pos55 (at 2650 m a.s.l.; Fig. 1) was mounted on the tongue of a rock glacier that is about $130 \mathrm{~m}$ wide, $600 \mathrm{~m}$ long and up to $40 \mathrm{~m}$ thick (Delaloye et al., 2013). In 2008, the rock glacier had an average horizontal displacement of about $0.5 \mathrm{~m}$ per year (measured with InSAR; Strozzi et al., 2009). The velocity of the tongue has continuously increased since 2007 to up to $5 \mathrm{~m}$ per year in 2010/11 (measured with annually repeated GPS surveys; Delaloye et al., 2013). Station pos27 (3149 m a.s.l.; Fig. 1) was installed on a double ridge within a large deep-seated landslide. The entire landslide is about $450 \mathrm{~m}$ wide and $1 \mathrm{~km}$ long and has an elevation difference of about $650 \mathrm{~m}$. The average horizontal displacement is approximately $0.5 \mathrm{~m}$ per year (Strozzi et al., 2009).

The GPS stations used (Fig. 1) are suitable for highmountain environments (Beutel et al., 2011; Buchli et al., 2012) and comprise a low-cost single-frequency GPS receiver and a two-axis inclinometer (see Fig. 2). Energy is provided by a photovoltaic system and a battery. The stations are installed on large boulders assumed to be carried along 
with the displacement of the entire slope. Nonetheless, an inference has to be made from this point measurement at the surface to the behaviour at depth or in a larger area around the measurement. A displacement measured at the surface could originate from translation of an entire slope or simply from local rotation of the boulder, on which the instrument is anchored (Fig. 3). For continuous monitoring, GPS antennae must be positioned above the expected snow depth to prevent signal loss even during wet snow conditions (Schleppe and Lachapelle, 2008). Therefore, the GPS antenna and inclinometer are mounted on top of a mast $\left(h_{\text {mast }}=1.5 \mathrm{~m}\right.$, Fig. 4$)$. A mast, however, makes the GPS signal more sensitive to local rotations that may then be misinterpreted as translations of the slope. Here, the measurement of mast inclination in combination with GPS allow us to separate translation and rotation components. The setup allows continuous measurements of positions and mast inclination with high temporal resolution (one GPS solution per day), temporal coverage of several years and high accuracy (subcentimetre accuracy; Buchli et al., 2012; Wirz et al., 2013). The instrumentation is described in more detail in Buchli et al. (2012) and Wirz et al. (2013).

\section{Data}

\subsection{GPS}

The data were collected from summer 2011 to summer 2012. GPS solutions have a temporal resolution of 1 day. The GPS solutions were calculated at the Geodesy and Geodynamics Lab of ETH Zurich, based on a single-frequency differential carrier-phase technique using the software Bernese (Limpach and Grimm, 2009; Dach et al., 2007) and provided a local Swiss projection (CH1903). Solutions are calculated with a static approach, using all daily measurements to compute a single and highly accurate daily solution (Buchli et al., 2012). The main error sources are satellite related (clock and orbit errors), atmosphere related (ionospheric and tropospheric delay), and receiver related (multipath or phasecentre variations; $\mathrm{Li}, 2011$ ). By applying a differencing static approach, most of these errors can be eliminated because similar influences on all nearby receivers cancel out (Gili et al., 2000; Den Ouden et al., 2010).

For each daily GPS position, the standard deviation of all components $(N, E, h)$ and their covariances are calculated. The standard deviation (usually less than a millimetre) describes the precision of the solution and is not a direct measure of the accuracy of the position (usually of $1 \mathrm{~cm}$ or less). The accuracy of the GPS positions cannot be calculated as no reference value is available. Nevertheless, the precision of the measurements can be estimated by calculating the standard deviation of the daily position values at a reference station.

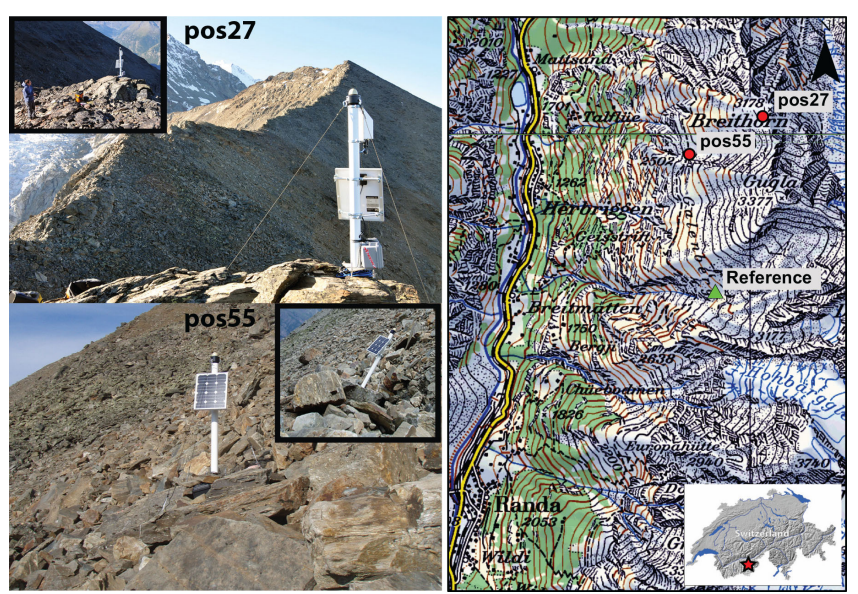

Figure 1. Locations and field impressions of the GPS stations of pos27 and pos55. The small photo (bottom right) shows GPS station pos55 at the end of June 2012, by then the station is strongly tilted towards the slope. Each GPS station includes a GPS antenna and two inclinometers that are mounted on top of a mast. The energy to operate the devices is provided by a photovoltaic energy harvesting system and backed by a battery. (Photos: V. Wirz and R. Delaloye.) LK200 from the year 2008 (reproduced with permission of swisstopo BA14054).

The reference station is assumed to be stable and is mounted on a large boulder on a flat meadow approximately $2 \mathrm{~km}$ away from the other stations.

The standard deviation of the error at the reference station over a period of several months (measured with the same devices) is $0.4 \mathrm{~mm}$ in the horizontal and $2.4 \mathrm{~mm}$ in the vertical. The range of the horizontal error is $2.8 \mathrm{~mm}$, and $12.7 \mathrm{~mm}$ for the vertical. In order to get realistic and conservative estimates of the position errors, the standard deviation of the daily solutions are multiplied by 10 as it is commonly done to estimate the actual standard deviation of GPS positions (P. Limpach, personal communication, 2013). This results in an estimated standard deviation of about $1.5 \mathrm{~mm}$ in the horizontal $(E, N)$ and about $3.5 \mathrm{~mm}$ in the vertical $(h)$, thus slightly higher than the precision of the positions of the reference station. The covariances between the components of the positions are typically very low $(<0.01 \mathrm{~mm})$. The standard deviations of the GPS solutions are shown in Fig. 2.

\subsection{Inclinometer}

A two-axis inclinometer (SCA830-D07, VTI Technologies, 2010) measures the tilt of the GPS mast in the two directions perpendicular to it ( $x$ and $y$ direction) with a temporal resolution of $5 \mathrm{~min}$. A rotation around the axis of the mast ( $z$ axis) is not measured. The accuracy of the sensor, described by its offset calibration error $\left(\right.$ at $\left.25^{\circ} \mathrm{C}\right)$ that includes a calibration error and drift over lifetime, is $\pm 1.1^{\circ}$ (VTI Technologies, 2010). Further noise is caused by environmental factors such as wind or temperature changes $\left( \pm 1.5^{\circ}\right.$ from -40 to $+125^{\circ}$, 

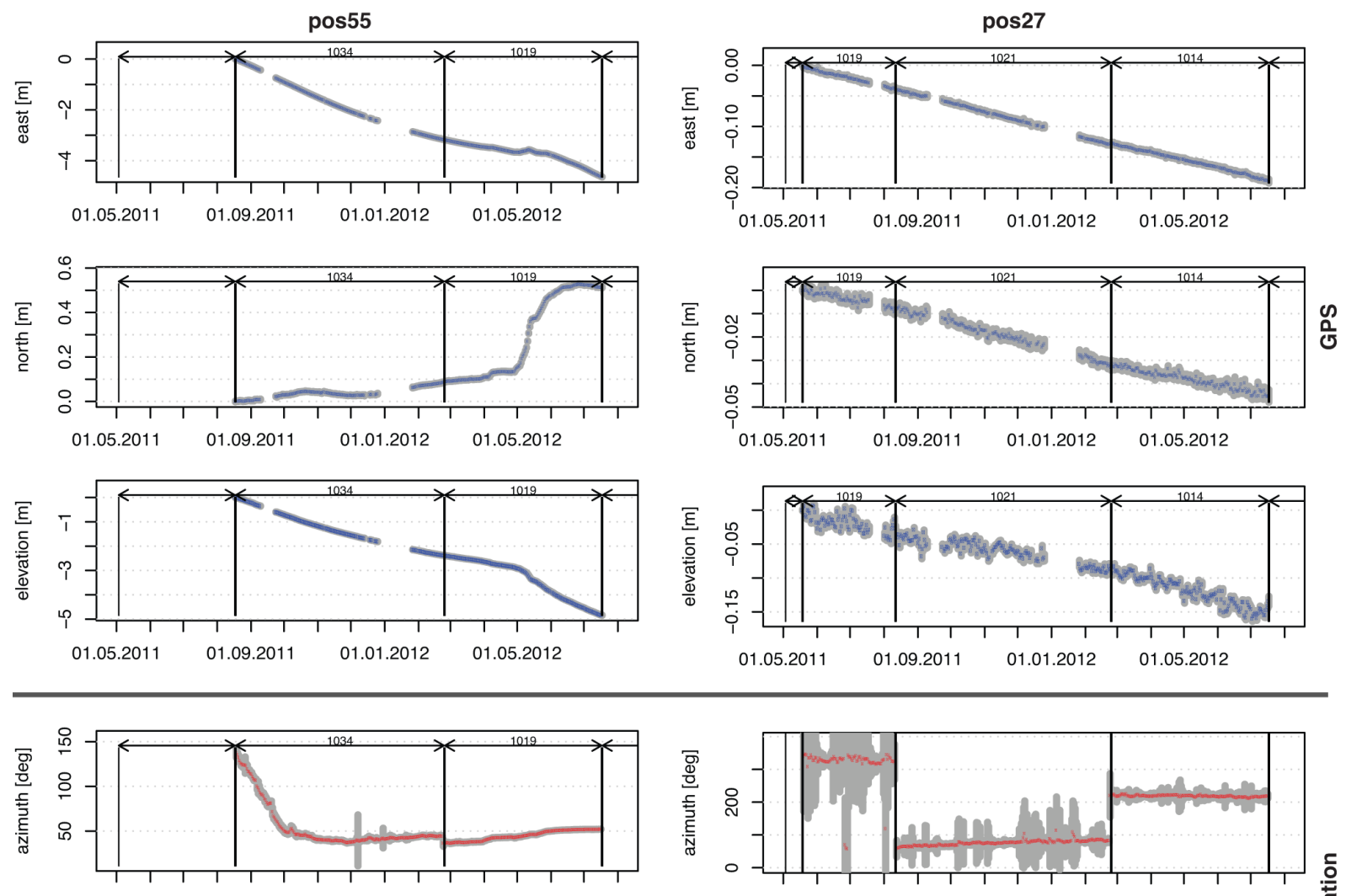

01.05.2011 01.09.2011 01.01.2012 01.05 .2012
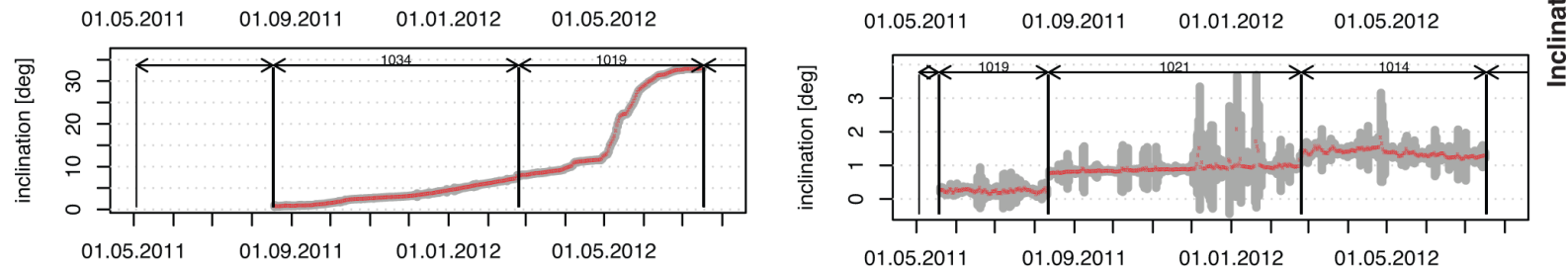

Figure 2. GPS positions $(E, N, h)$ and inclinometer measurements ( $\theta$ and its $a z$ ) of positions pos55 and pos27 and their error range ( \pm the standard deviation $\sigma$, in grey). The temporal resolution is 1 day. For better readability, the positions $(E, N, h)$ are given relative to the position at the start of the measurements. Note, that both axes differ for pos 55 and pos 27 . The vertical black lines indicate differing measurement devices (exchange of measurement device).

VTI Technologies, 2010). The resulting subdaily variations are small and no significant correlation with wind or air temperature measured at a co-located meteorological station was found. Daily median, standard deviation, and covariance of inclination were calculated from the raw measurements. The standard deviation is typically $0.1^{\circ}$, ranging from 0.001 to $0.2^{\circ}$ (Fig. 2) and covariances are relatively small (median: $0.0004^{\circ}$ for pos55 and $0.04^{\circ}$ for pos 27 ).

Two assumptions are necessary to calculate the tilt of the GPS mast: (a) no rotation occurs around the $z$ axis (Fig. 4) as this is not measured in the current setup, and (b) the centre of rotation lies on the $z$ axis. We distinguish a local coordinate system that differs between devices and that is given by the directions of their two inclinometers, and a global coordinate system (CH1903) in which the GPS solutions are delivered. In order to detect a rotation of the mast around the $z$ axis and to transform the local coordinate system to $\mathrm{CH} 1903$, the orientation of the mast (mast.o; Fig. 4) is measured manually in the field when deploying or exchanging a device. The manual measurements of orientation have a precision of approximately $5^{\circ}$.

The inclination $\theta$ and its azimuth $\phi$ of the mast tilt in the local coordinate system are calculated with rotation matrices (for detail see, Eq. A1 in Appendix). $\phi$ in the local coordinate system is transformed into CH1903 ( $a z$, in degrees eastwards from north) using the sign of the raw inclination measurements and mast.o. The inclinometer data, which have a sampling interval of $5 \mathrm{~min}$, are aggregated daily to the median value. 


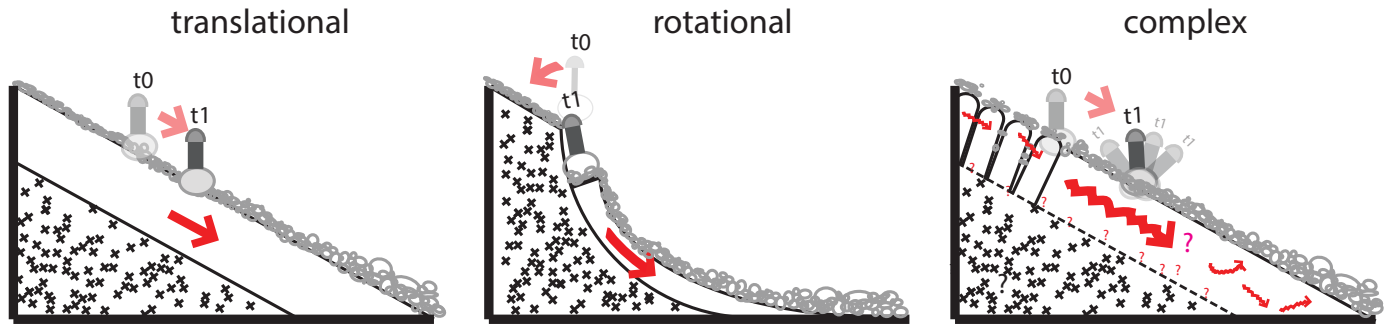

Figure 3. Schematic of differing slides and possible sources of rotation/translation (modified after Varnes, 1978): (a) translational slide with failure plane paralleling surface, (b) rotational slide with surface of rupture curved concavely upward, and (c) complex slide with various (unknown) types of slides involved and local rotation of a small volume below the GPS station.

\subsection{Combination of GPS and inclinometer data}

The inclinometer measurements are used to correct the GPS positions (measured at the top of the mast) for tilt of the mast. Based on daily $\theta$ and $a z$ of the mast's tilt, the position of the foot (the positions corrected for the mast tilt: $E_{\mathrm{f}}, N_{\mathrm{f}}, h_{\mathrm{f}}$ ) is computed using standard trigonometry.

The assumption that the mast foot is the centre of rotation is further investigated. Assuming that the real centre of rotation remains constant in time and lies on the $z$ axis, its location (e.g. within the boulder the mast is mounted on) is approximated by increasing the mast height $\left(h_{\text {mast }}\right)$. With the best approximation of the true centre of rotation, the estimated MP, especially the direction of movement, should be smoothest.

\section{Methods}

\subsection{SNRT}

The aim of this study was to develop a method sensitive to the uncertainty of the data. Two movement parameters are calculated with SNRT: magnitude of the velocity ( $v$, in this paper referred to as velocity) and direction of movement ( $\left.\mathrm{azi}_{v}\right)$. The applied smoothing window depends on the SNR; i.e. for each velocity period the SNR must be higher than a predefined threshold. The SNR is estimated using Monte Carlo simulations.

\subsubsection{Calculation of movement parameters}

Velocities $(v)$ are calculated based on linear fits through daily positions as a function of time (Appendix Fig. B1). The direction of movement $\left(\mathrm{azi}_{\mathrm{v}}\right)$ is derived and given as degrees eastwards from north:

$\operatorname{azi}_{\mathrm{v}}=\frac{N}{\sqrt{E^{2}+N^{2}}+E}$

Velocities are calculated for the positions of the GPS antenna and the mast foot (see Sect. 3.3). In order to find time windows with a SNR higher than a predefined threshold, we loop through all data points using increasing window sizes $w$ and test if the SNR criterium is fulfilled; i.e. that the SNR is higher than the threshold. The selection of the smoothing window in SNRT is further described with pseudocode and a figure in Appendix B. The SNR is given as

$\mathrm{SNR}=\frac{\left|\mu_{\mathrm{v}}\right|}{\sigma_{\mathrm{v}}}$,

with $\mu_{\mathrm{v}}$ being the mean and $\sigma_{\mathrm{v}}$ the standard deviation of velocity over all realizations of MCS.

For each estimated velocity period, the start and end date, the mean velocity $\mu_{\mathrm{v}}$, the median of the direction of movement $\left(\mathrm{azi}_{\mathrm{v}}\right)$, the standard deviation of velocity $\sigma_{\mathrm{v}}$, the standard deviation of the direction of movement $\sigma_{\mathrm{azi}-\mathrm{v}}$, and its SNR are stored. MPs are calculated separately for periods with differing measurement devices if these have been exchanged during field visits. This is because the slight offsets between differing inclinometers and antennae would otherwise cause artefacts in the resulting MPs.

For the velocity estimations of pos 27 and pos55 different parameter values are applied for the threshold $(t=3,5,10$, $15,20,30,40$ or 50$)$ and the mast height $\left(h_{\text {mast }}=1.5,2,2.5\right.$, 3 , or $3.5 \mathrm{~m})$.

\subsubsection{Uncertainty estimation}

A Monte Carlo simulation (MCS) is useful for estimating the uncertainty of model outputs and has previously been applied to the estimation of MPs from GPS positions (Mair et al., 2001; Laube and Purves, 2011). In this study, MCS is used to estimate the uncertainty (SNR) of MPs derived for the GPS antenna and mast foot (corrected for the tilt of the mast). In each realization, the error is sampled from a multivariate normal distribution (with $\mu=0 \mathrm{~m}$, and the covariance matrix) and added to the measured data and the resulting MPs are recalculated. We assume that the data are neither temporally nor spatially autocorrelated. This is a conservative assumption. Estimated errors are likely to be higher than those from spatially and temporally autocorrelated data (Laube and Purves, 2011). Based on the modelled positions MPs are then calculated (see Sect. 4.1.1). We distinguish MPs in 1-D, 2-D (horizontal velocity) and 3-D. For MPs at the mast foot, the 


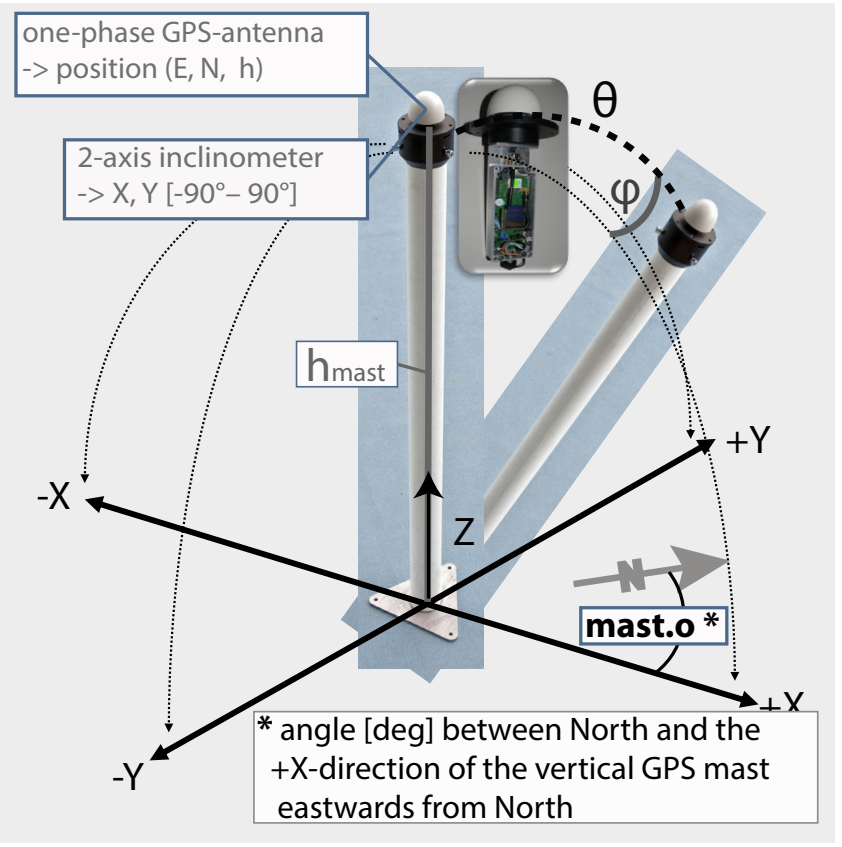

Figure 4. Terms and conventions used: measurement setup with single-phase GPS receiver and two inclinometers. The tilt of the GPS mast is measured with two inclinometers installed perpendicular to the GPS antenna. This setup allows us to calculate $\theta$ and $\phi$ of the tilted GPS mast.

error of the inclinometer data (with $\sigma_{\text {theta }}$ and $\sigma_{\mathrm{az}}$ ) and the ori-

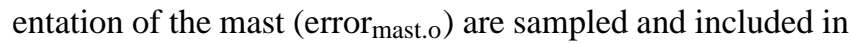
addition to the errors of the GPS position. The uncertainty of mast.o is sampled from a normal distribution (with $\mu=0^{\circ}$, and $\sigma=5^{\circ}$ ), and mast.o remains constant for the entire period during which a device is installed at a site.

In order to limit computational effort, we test the stability of the results after every additional 250 realizations. If the standard deviation of the SNR over the last 250 realizations (Eq. 3) is smaller than 0.08 the MCS is stopped. Otherwise, they are continued up to a maximum of 2000 realizations. The standard deviation of the SNR over the last 250 additional realizations is calculated as follows:

$$
\begin{aligned}
\sigma_{\mathrm{SNR}} & =\sqrt{\operatorname{VAR}\left(\mathrm{SNR}_{\mathrm{all}}\right)}, \\
\text { with } \mathrm{SNR}_{\text {all }} & =\left[\mathrm{SNR}_{i+1}, \mathrm{SNR}_{i+2}, \ldots, \mathrm{SNR}_{i+250}\right],
\end{aligned}
$$

where $i$ refers to the previously done realizations $(i=$ $[250,500,750, \ldots, 1750], \mathrm{SNR}_{i+1}$ is the SNR of the velocity calculated including all previously performed realizations $(i)$ plus one additional realization, and $\mathrm{SNR}_{i+250}$ is the SNR of the velocity calculated including also all the additional 250 realizations.

\subsection{Sensitivity testing}

The performance of SNRT was tested using three types of synthetic time series designed to represent typical patterns
Table 1. Summary of the errors for the different methods: SNRT (with different thresholds: 5, 20, and 50), simple, spline, and lokern. Errors are defined as the mean of the absolute difference between estimated velocities and the reference velocity $v_{\text {true. The errors are }}$ given as $10^{-4} \mathrm{~m} \mathrm{~d}^{-1}$. Bold numbers indicate the smallest errors for each test-case (e.g. 0.81 for A-a).

\begin{tabular}{lrrrrrr}
\hline Case & Simple & SNRT-5 & SNRT-20 & SNRT-50 & Spline & Lokern \\
\hline A-a & 48.56 & 2.60 & $\mathbf{0 . 8 1}$ & 2.60 & 1.01 & 1.25 \\
A-b & 4.27 & 1.64 & 0.63 & 1.64 & 1.46 & $\mathbf{0 . 4 4}$ \\
A-c & 0.53 & 0.54 & 0.38 & 0.54 & 1.41 & $\mathbf{0 . 1 5}$ \\
& & & & & & \\
B-a & 49.52 & 2.28 & 3.20 & 3.20 & $\mathbf{1 . 4 7}$ & 2.51 \\
B-b & 4.54 & 1.15 & 1.15 & 1.48 & 1.36 & $\mathbf{0 . 2 7}$ \\
B-c & 0.50 & 0.44 & 0.31 & 0.82 & 1.38 & $\mathbf{0 . 0 5}$ \\
& & & & & & \\
C-a & 41.71 & 10.97 & 13.87 & 16.50 & 29.24 & $\mathbf{9 . 1 1}$ \\
C-b & 5.13 & $\mathbf{2 . 2 0}$ & 4.80 & 9.86 & 29.09 & 2.32 \\
C-c & $\mathbf{0 . 6 2}$ & $\mathbf{0 . 6 2}$ & 0.93 & 0.91 & 29.07 & 1.08 \\
\hline
\end{tabular}

of slope movements: (A) slow linear displacement with two periods of slightly different velocities $\left(v_{1}=5, v_{2}=13\right)$, (B) velocity following a sine function $\left(\sigma_{\mathrm{v}}=5\right)$, and (C) slow linear displacement with a short peak of high velocity (quarter sine function, 15 data points). For each pattern (A, B, C), we generated three cases based on differing random noise levels: (a) noise level equal to 10 times the lowest, respectively its mean (case B) velocity $\left(\sigma_{\text {noise }}=10 \times v_{\text {min, mean }}\right)$, (b) noise level equal to the lowest (case B: $\min )$ velocity $\left(\sigma_{\text {noise }}=\right.$ $\left.v_{\text {min, mean }}\right)$, and (c) noise level is 10 times smaller than the lowest (case B: $\min )$ velocity $\left(\sigma_{\text {noise }}=v_{\text {min, mean }} \times 10^{-1}\right)$. For comparison, also the simple velocity calculations $(\Delta$ dist $/ \Delta t$ of the unfiltered time series), the cubic smoothing spline function (spline; Hastie and Tibshirani, 1986; Chambers and Hastie, 1992, using the R function smoothing.spline), and kernel regression smoothing with local plug-in bandwidth (lokern; Gasser et al., 1991; Seifert et al., 1994, using the R function lokern), were used to estimate velocities. For SNRT, 500-2000 realizations were used in the MCS and differing thresholds $(5,20,50)$ were applied. The optimal smoothing parameter (spar) for spline was determined using leaveone-out cross-validation. We tested the errors of the residuals of the first derivation of spline functions with different smoothing-parameters. The lokern function was parameterized assuming heteroscedastic error variables for the variance estimation, and the variance of the error variables was set to be twice the variance of the position data.

\section{Results and interpretation}

\subsection{Sensitivity tests with synthetic data}

At most, 1750 realizations are needed to obtain stable standard deviations of the SNR $\left(\sigma_{\mathrm{SNR}}<0.8\right)$ during MCS. 


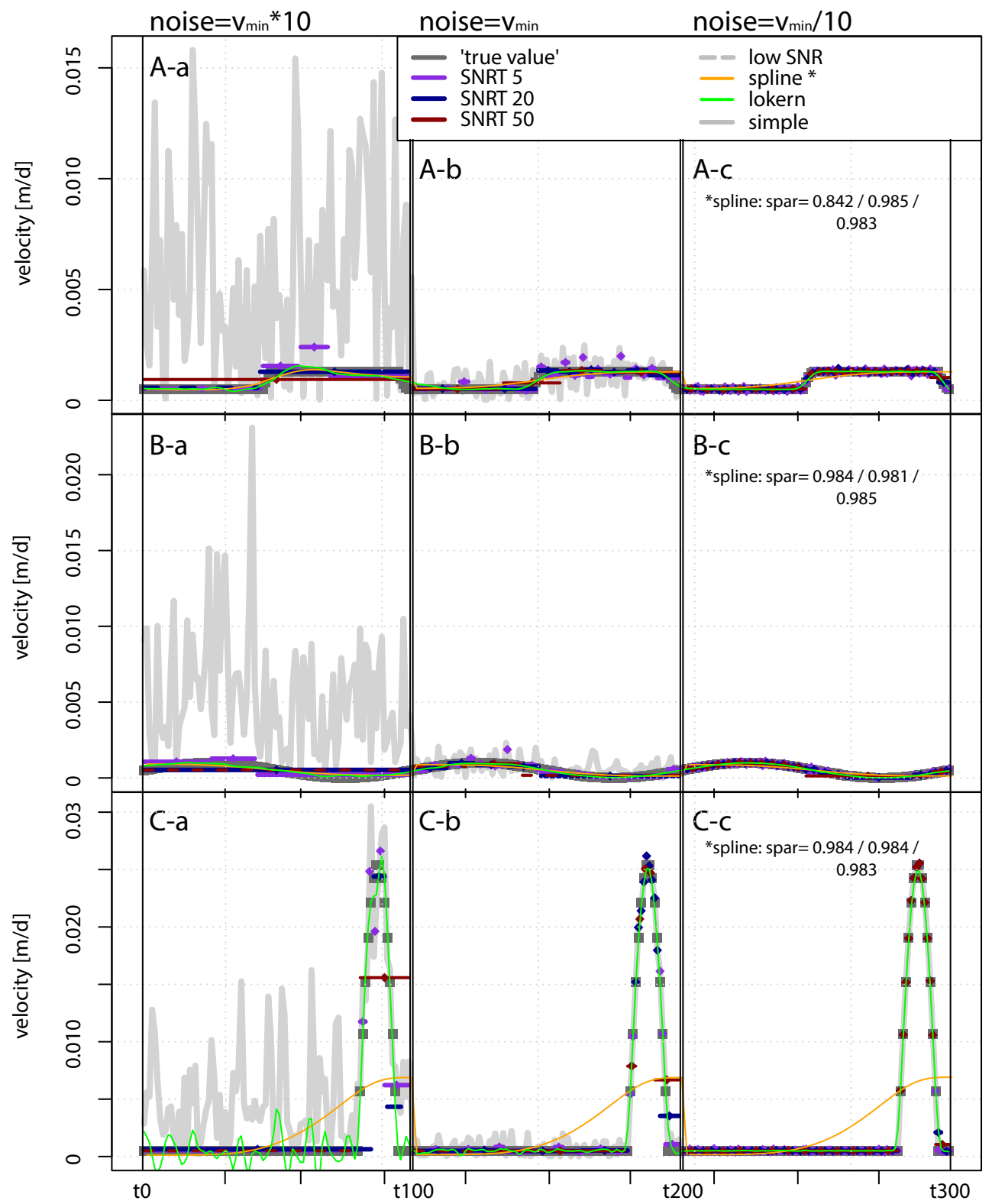

Figure 5. Synthetic time series of positions following (A) linear displacement, (B) following sine function, and (C) linear displacement with short peak in velocity. For each time series three different periods with different noise levels are modelled $\left(\mathbf{a}: \sigma_{\text {noise }}=v_{\text {min }} \times 10 ; \mathbf{b}\right.$ : $\sigma_{\text {noise }}=v_{\min } ; \mathbf{c}: \sigma_{\text {noise }}=v_{\min } \times 10^{-1}$ ). The velocity of the displacement without noise (the "true" velocities) are plotted in dark grey with white dots. Velocities have been estimated with different methods (SNRT: blue, violet and dark red; simple: grey; spline: orange; and lokern: green). Periods with a SNR below the threshold $t$ (SNRT 5, 20, or 50) are indicated with dashed lines.

Figure 5 shows estimated velocities for the synthetic time series, calculated with the different methods. An overview of the resulting errors (difference to reference velocity without noise, $\left.v_{\text {true }}\right)$ is given in Table 1 . The results of SNRT obviously depend on the threshold chosen. For case A (all noiselevels), errors are smallest when a threshold of 20 is used. For cases B and C, the smallest errors are mostly obtained with a threshold of 5. However, for case A with a threshold of 5 the temporal variability is overestimated for a medium-high noise level. Often, the largest error occurs with a threshold of 50. Here, for case A-a or B-a no distinction between periods of different velocities is made anymore. In most cases the SNR is close to the threshold but in some periods it stays below it (e.g. in A-a with a threshold of 20, one period has an SNR of 9.5). In general, the differences between estimations with different thresholds are smaller than between different methods, especially for high noise levels (Table 1). 

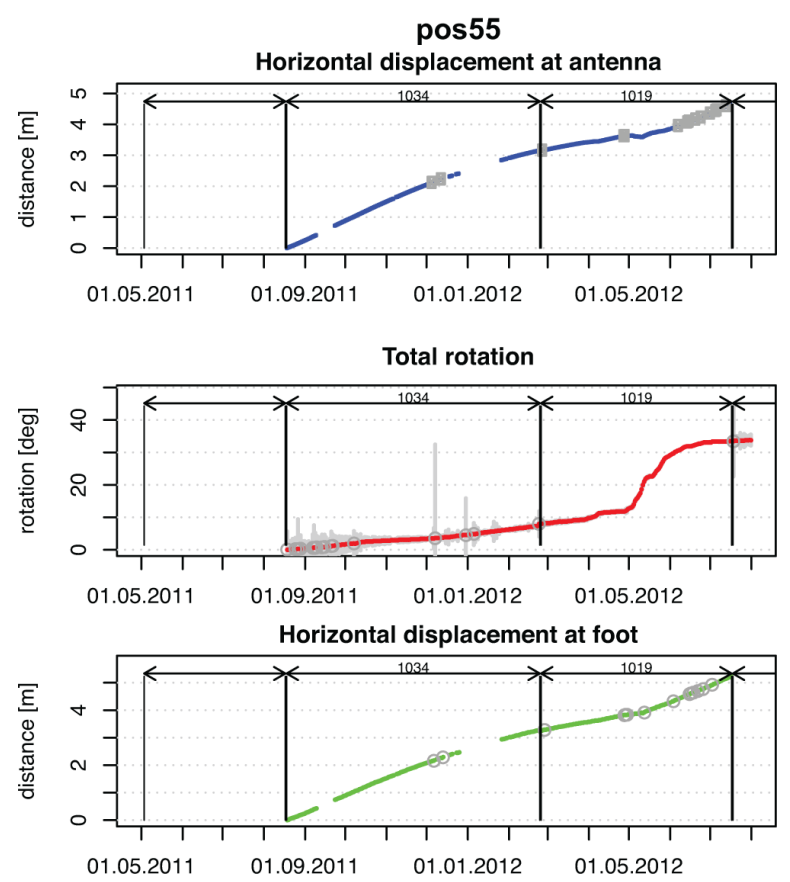
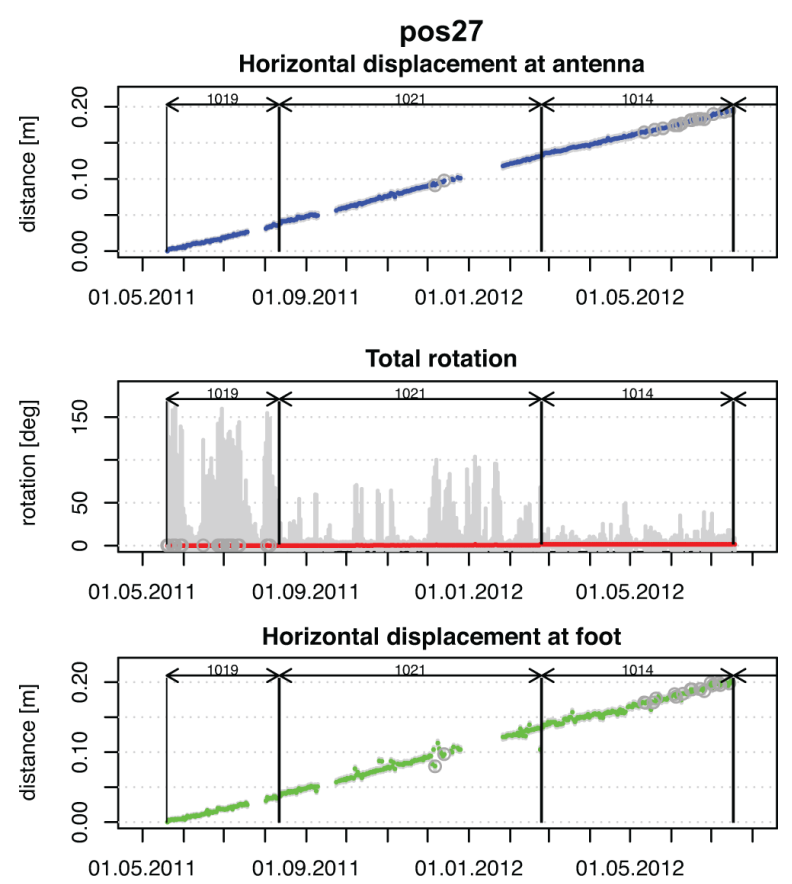

Figure 6. Total displacement at pos55 and pos 27 of the GPS position at the antenna, the inclinometer measurements and the position of the GPS foot (corrected for mast tilt). Data points with an error (in the original data) that is higher than the $95 \%$ quantile are marked with grey circles. The uncertainty $(\sigma)$ of the cumulative distance (grey) is estimated using 2000 MCS (Sect. 4.1.2). Note that both axes differ for pos55 and $\operatorname{pos} 27$.

If the noise is high compared to the velocity, errors are generally, unsurprisingly, largest independently of the method applied. The main differences to the true velocity occur if the simple method is applied $\left(41.7 \leq\right.$ error $_{\text {simple }} \leq$ 48.6). $v_{\text {simple }}$ strongly overestimates $v_{\text {true }}$ for all patterns (A-a, B-a, C-a). If the noise is high, for case A the errors are smallest with SNRT and a threshold of 20 (errorsNRT $=$ 0.81 ), and for cases B and C with lokern (error ${ }_{\text {lokern }} \leq 2.51$ ). However, $v_{\text {lokern }}$ overestimates the variability during the period of constant displacement in case $\mathrm{C}$, and the timing of acceleration in case A-a is incorrect. With SNRT, errors are low in comparison $\left(0.3 \leq\right.$ error $\left._{\mathrm{SNRT}} \leq 16.5\right)$ and the patters are mostly well reproduced for cases A-a and C-a. However, $v_{\text {SNRT }}$ does not depict the sinusoidal form of $v_{\text {true }}$ in B-a. Using spline, errors are comparably small for cases A and B $\left(1 \leq\right.$ error $\left._{\text {spline }} \leq 1.5\right)$, but the high velocities in the speed-up event (case C-a) are smoothed. Hence, error $r_{\text {spline }}$ is large for case $\mathrm{C}$-a $\left(\right.$ error $\left._{\text {spline }}=9.11\right)$. Furthermore, the timing of acceleration in case A-a is not correct for $v_{\text {spline. If the noise is }}$ similar to the velocity, errors are strongly reduced compared to the high noise level. Nonetheless, estimated velocities with the simple method show strong, spurious, fluctuations. With SNRT, the three movement patterns are well reproduced and errors are similar to those from spline or lokern. In particular, for periods of constant linear displacements, the errors of $v_{\text {SNRT }}$ tend to be smaller compared to the other methods. However, $v_{\text {lokern }}$ is mostly the smallest. With spline, the si- nusoidal form (B-b) is well depicted, but the sudden peak in $\mathrm{C}-\mathrm{b}$ is smoothed out. If the noise is small compared to the velocity, errors and differences between the methods and parameter settings become small. The largest errors occur for C-c. Here, error ${ }_{\text {spline }}$ is the highest (29.07). error lokern $_{(\leq 0.2)}$ is small for cases A-c and B-c. The smallest errors for C-c result with the simple method (error simple $=0.62$ ).

\subsection{Estimation of movement parameters from field measurements}

The total displacement measured at the antenna of pos55 in the study site over a period of 355 days was $4.65 \mathrm{~m}(\sigma=$ $3.3 \mathrm{~mm}$; Fig. 6). The total displacement of the mast foot, corrected for rotation, was $5.22 \mathrm{~m}(\sigma=3.2 \mathrm{~mm})$. The total rotation of the mast was $33.4^{\circ}$ and strongly accelerated in May 2012. During a period of about 1 month, the inclination of the mast increased by $20^{\circ}$. At pos 27 the total displacement at the antenna over a period of 426 days was $19.5 \mathrm{~cm}$ $(\sigma=4 \mathrm{~mm})$, similar to the cumulative displacement of the mast foot $(19.8 \mathrm{~cm}$ with $\sigma=3.8 \mathrm{~mm})$. The total rotation was $1.4^{\circ}$.

Velocities $(v)$ and direction of movement $\left(\operatorname{azi}_{\mathrm{v}}\right)$ for pos 27 and pos55 are estimated using different parameters for $t$ and $h_{\text {mast }}$ (Sect. 4.1.1). Here, mainly the differences caused by applying different thresholds are shown. For pos 27 and pos55 a maximum of 1250 and 2000 realizations, respectively, are required during MCS to obtain stable results 

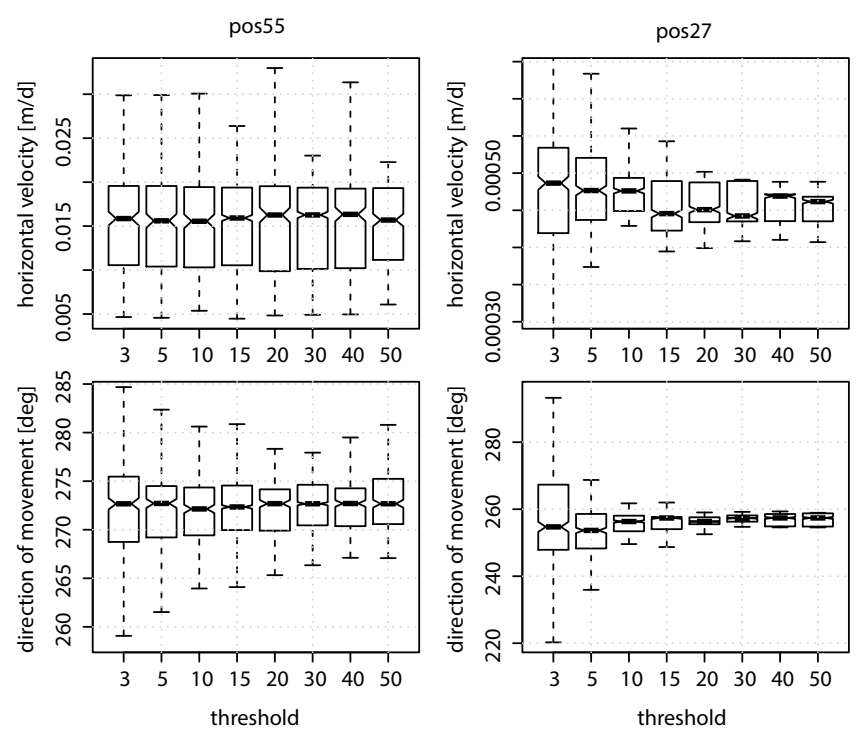

Figure 7. Distribution of the horizontal velocities (upper plots) and the direction of the movement (azi $\mathrm{v}_{\mathrm{v}}$, lower plot) calculated with SNRT applying different thresholds. Note that the $y$ axes differ for pos55 and $\operatorname{pos} 27$.

$\left(\sigma_{\mathrm{SNR}}<0.8\right)$. Differences caused by differing thresholds are summarized with box-and-whisker plots (Fig. 7). For pos27, both the median and the range of the velocities decrease with increasing thresholds. In addition, the range of azi decreases with higher thresholds. For a threshold of 15 or higher the median for both $v$ and azi $\mathrm{i}_{\mathrm{v}}$ remain rather constant $\left(4.6 \times 10^{-4} \mathrm{~m} \mathrm{~d}^{-1}\right.$ in $256^{\circ}$ eastwards from north). By contrast, for pos 55 the median of the velocity slightly increases with increasing thresholds, but remains more or less constant $\left(0.17 \times 10^{-2} \mathrm{~m} \mathrm{~d}^{-1}\right)$. The range of velocities does not decrease with higher thresholds. The range of azi $i_{v}$, however, is smaller for thresholds above 20 than for low ones (3 and 5).

The temporal variability of velocity and the direction of movement were larger at pos55 than at pos27 (Fig. 8). At pos55 $v$ varied between 30 and $233 \%$ and azi v $_{\mathrm{v}}$ between 3 and $113 \%$ compared to the mean value $(t=15)$. At pos 27 , the differences to the mean were only $89-112 \%$ for $v$ and $96-$ $104 \%$ for azi $\mathrm{i}_{\mathrm{v}}(t=15)$. Velocities at pos55 followed a seasonal cycle with higher values in summer, but a more or less constant azi $\mathrm{ai}_{\mathrm{v}}\left(270^{\circ}\right)$. In May 2012, velocities suddenly increased from about 1 to up to $4 \mathrm{~cm} \mathrm{~d}^{-1}$ and the direction of movement changed. This peak lasted for about 1 month. At pos27, no obvious seasonal pattern is visible although periods of slightly different velocities can be identified: velocities were generally highest in autumn (October) and lowest at the end of winter (February/March).

Figure 8 illustrates velocities estimated with different methods. At pos55, during periods of rather constant displacement (e.g. March 2012) differences between the methods are relatively small. The main differences between the methods occurred around data gaps (e.g. March 2011) or in spring 2012 (mainly May) when velocities accelerated. While $v_{\text {SNRT }}$ increased to nearly $4 \mathrm{~cm} \mathrm{~d}^{-1}$ in spring, the maxima of $v_{\text {spline }}$ is about $1 \mathrm{~cm} \mathrm{~d}^{-1}$ and the maxima of $v_{\text {lokern }}$ is $2 \mathrm{~cm} \mathrm{~d}^{-1}$. Around data gaps, $v_{\text {spline }}$ is higher than $v_{\mathrm{SNRT}}$ or $v_{\text {simple }}$, and $v_{\text {lokern }}$ is lower. In December 2011, various periods of the temporal variability of $v_{\mathrm{SNRT}}$ are comparably high. The differences between $v_{\text {SNRT }}$ with different thresholds are small. For pos27, the differences between the methods are generally large. $v_{\text {simple }}$ was higher and fluctuated stronger compared to the other methods. The temporal variability of $v_{\text {lokern }}$ is also higher compared to $v_{\text {SNRT }}$. Differences between $v_{\text {SNRT }}$ and $v_{\text {spline }}$ mainly occur around data gaps. As for pos55, the differences between $v_{\mathrm{SNRT}}$ with different thresholds are small.

\subsection{Correction for mast tilt}

At pos55 the course of the relative horizontal positions of the mast foot (corrected for the mast tilt) over time is more linear (similar direction of movement) compared to that of the antenna (Fig. 9). The difference between antenna and foot increases with time as the tilt of the GPS mast increases. For pos27, the differences between the displacement at the antenna and the foot are small (Figs. 2, 9). Here, the main difference in the positions of the GPS foot occur during device changes. The assumption that the centre of the rotation of the station is assumed to be equal to that of the mast foot is possibly not realistic, as stations are mounted on large boulders. By increasing $h_{\text {mast }}$, a centre of rotation is modelled, which lies on the $z$ axis below the foot (within the boulder; Fig. 9, pos55). The displacement appears most linear when $h_{\text {mast }}$ is set to $2.5 \mathrm{~m}$, suggesting that this may be a useful correction. However, differences become very small if the velocity of the antenna and the foot are summarized, e.g. mean velocity.

\section{Discussion}

\subsection{Comparison of methods and parameter settings}

The results of the sensitivity tests with synthetic time series are summarized in Table 2. For a low noise level, the performance of all methods is satisfactory, even with the simple method (Fig. 5). However, if noise levels are equal to, or higher, than the signal (velocity), calculated velocities clearly depend on the applied method and parameter setting. For high noise levels, the smallest errors are obtained for cases $\mathrm{C}$ and B with lokern, and for case A with SNRT using a threshold of 20. The largest errors occur with a strongly variable SNR (C-c). All methods, except for SNRT, overestimate temporal variability during periods of constant linear displacement. Only SNRT performs well both for the period of constant velocity and the sudden peaks but the error is comparably high. The main reason for this is a misrepresentation of the timing of acceleration: due to the high noise, the periods 
Table 2. Summary of the sensitivity tests for the different methods and noise levels. In addition, for each method, suitable applications using GPS data with an accuracy on the order of millimetres to a few centimetres are given. Methods have been applied to estimate the velocities for synthetic time series with three different movement patterns (A, B, C) and noise levels (a, b, c; see Sect. 5.1). For SNRT it is distinguished between the different thresholds $(t=5,20,50)$.

\begin{tabular}{|c|c|c|c|c|c|}
\hline \multirow[t]{2}{*}{ Name } & \multicolumn{3}{|c|}{ Noise-level: } & \multirow[t]{2}{*}{ Evaluation } & \multirow[t]{2}{*}{ Suitable application } \\
\hline & low (c) & medium (b) & high (a) & & \\
\hline Simple & Good performance & $\begin{array}{l}\text { Overestimation of the temporal vari- } \\
\text { ability }\end{array}$ & $\begin{array}{l}\text { Overestimation of the velocity and its } \\
\text { temporal variability; movement pat- } \\
\text { terns not represented }\end{array}$ & $\begin{array}{l}\text { + suitable for time series with low } \\
\text { noise level - not suitable for medium- } \\
\text { high noise levels }\end{array}$ & $\begin{array}{l}\text { Displacement per time larger than about } 10 \text { times the } \\
\text { standard deviation of the error of GPS solutions and } \\
\text { smooth transitions between periods of slow and fast } \\
\text { movement. Examples are } \\
+ \text { fast moving glaciers } \\
+ \text { ice islands or ice bergs }\end{array}$ \\
\hline SNRT & $\begin{array}{l}\text { Good performance for all } \\
\text { parameter-settings (thresh- } \\
\text { old } t \text { ) }\end{array}$ & $\begin{array}{l}\text { Generally good performance, espe- } \\
\text { cially with } t=20 ; t=5 \text { : slightly over- } \\
\text { estimation of the temporal variability; } \\
t=50 \text { : timing of acceleration some- } \\
\text { times not fully correct due to large } \\
\text { smoothing windows }\end{array}$ & $\begin{array}{l}\text { Generally good performance, espe- } \\
\text { cially for C-a; } t=5: \text { temporal variabil- } \\
\text { ity slightly overestimated; } t=20 / t= \\
50 \text { : movement patterns of A-a and B- } \\
\text { a not well represented due to large } \\
\text { smoothing windows }\end{array}$ & $\begin{array}{l}\text { Returns discrete reliable velocity esti- } \\
\text { mations representative for given peri- } \\
\text { ods } \\
+ \text { suitable for various noise levels and } \\
\text { variable SNR } \\
\text { - for high noise levels timing of } \\
\text { acceleration not correct due to large } \\
\text { smoothing-windows }\end{array}$ & $\begin{array}{l}\text { Reliable velocity estimations even for velocities much } \\
\text { smaller than } 10 \text { times the standard deviation of the er- } \\
\text { ror of GPS solutions and where the SNR potentially } \\
\text { changes over time. Examples are } \\
\text { + deep-seated landslides ( }>1 \mathrm{~mm} / \mathrm{d} \text {, potentially with } \\
\text { sudden acceleration) } \\
\text { + rock glacier movements, potentially with sudden ac- } \\
\text { celeration in spring } \\
\text { + gelifluction, with sharp acceleration during snowmelt } \\
\text { + slow-moving glaciers, such as seracs on hanging } \\
\text { glaciers }\end{array}$ \\
\hline Spline & $\begin{array}{l}\text { Generally good perfor- } \\
\text { mance, except for C-c; } \\
\text { timing of acceleration not } \\
\text { fully accurate (e.g. A-c) }\end{array}$ & $\begin{array}{l}\text { Generally good, but timing of acceler- } \\
\text { ation not fully accurate and underesti- } \\
\text { mation of sudden peak in velocity (C- } \\
\text { b) }\end{array}$ & $\begin{array}{l}\text { Generally good performance, but tim- } \\
\text { ing of acceleration not correct in A-a } \\
\text { and C-a }\end{array}$ & $\begin{array}{l}\text { + suitable for time series with smooth } \\
\text { accelerations (sinusoidal movement- } \\
\text { patter) } \\
\text { - not suitable for time series with vari- } \\
\text { able SNR }\end{array}$ & $\begin{array}{l}\text { Velocity estimation of movements with smooth accel- } \\
\text { eration ( sinusoidal velocity regime). Examples are } \\
\text { + rock glaciers with sinusoidal movement-regime } \\
\text { + deep-seated landslides in seasonal frost }\end{array}$ \\
\hline Lokern & Good performance & $\begin{array}{l}\text { Generally good performance, but tem- } \\
\text { poral variability in C-b overestimated }\end{array}$ & $\begin{array}{l}\text { Temporal variability slightly overesti- } \\
\text { mated (clear overestimation of tempo- } \\
\text { ral variability in C-a), timing of accel- } \\
\text { eration not fully accurate (A-a) }\end{array}$ & $\begin{array}{l}\text { + suitable for time series with variable } \\
\text { SNR and low to medium noise level } \\
\text { - for a high noise level and variable } \\
\text { SNR the temporal variability is overes- } \\
\text { timated }\end{array}$ & $\begin{array}{l}\text { Detection of the timing of acceleration, for various } \\
\text { movement regimes, even for high noise levels and vari- } \\
\text { able SNR. Examples are } \\
+ \text { glaciers with medium velocity and sudden accelera- } \\
\text { tion or deceleration } \\
\text { + very fast rock glaciers or landslides }\end{array}$ \\
\hline
\end{tabular}
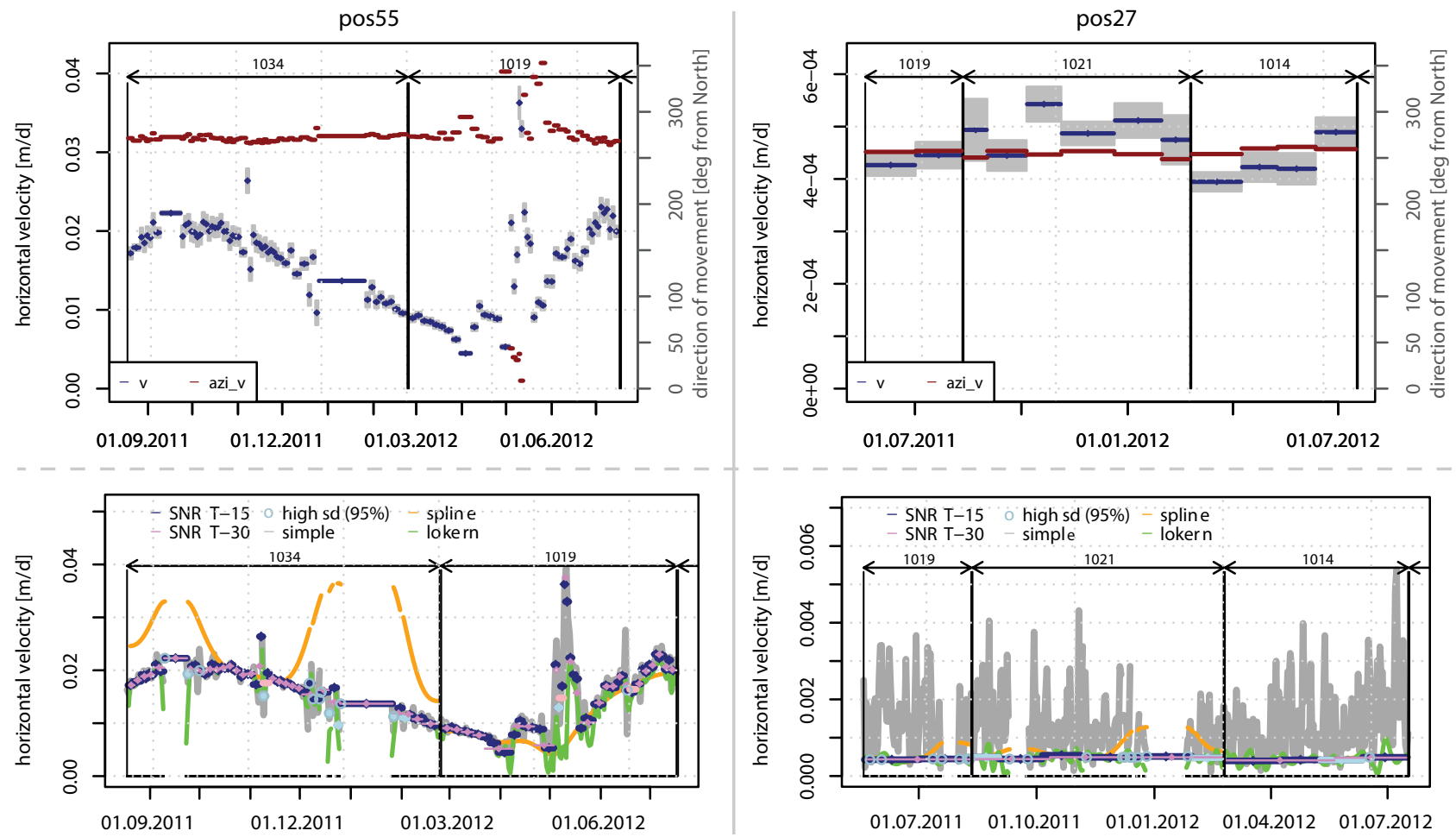

Figure 8. Top: Horizontal velocity and $\mathrm{azi}_{\mathrm{v}}$, calculated with SNRT and a $t$ of 15 . Periods with a SNR smaller than the predefined $t$ are plotted in light blue. Bottom: comparison of different methods to estimate the horizontal velocity at pos 27 and pos55. Next to the velocities estimated with SNRT and $t$ of 15 or 30 , also the simple, ( $\triangle$ dist/ $\triangle t$ of the unfiltered GPS positions), spline and lokern methods are also applied. Data points in the GPS data, with a standard deviation higher than the $95 \%$ quantile are indicated with light blue circles. 

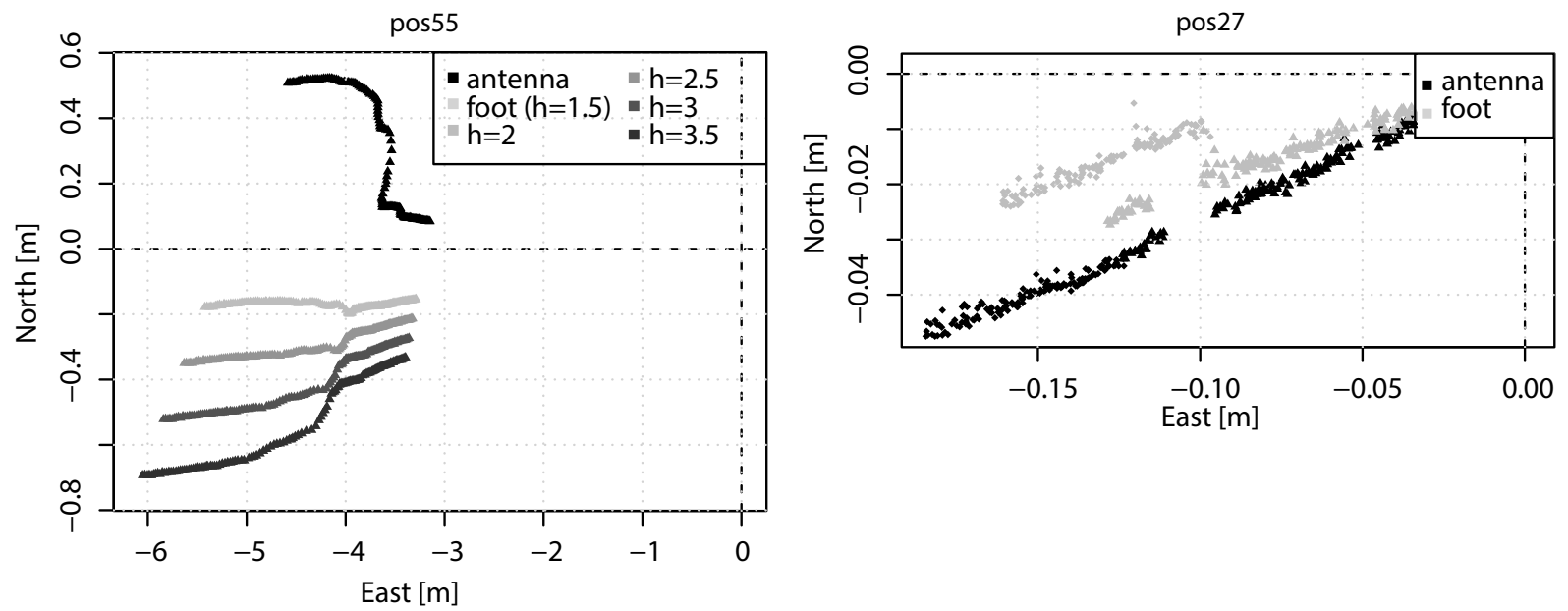

Figure 9. East and north positions of the antenna (black) and foot (grey) for pos55 and pos27. Note that the range of both axes differ. For pos55, additional positions of the foot that are corrected for the rotation of the GPS mast based on using different distances to the GPS antenna $\left(h_{\text {mast }}=2,2.5,3\right.$ and $\left.3.5 \mathrm{~m}\right)$ are shown.

become comparably large and hence the timing of acceleration is not accurately captured.

For medium-high noise levels, the data need to be filtered to obtain realistic velocity estimations. Differences between noise levels and parameter settings are larger for $v_{\text {spline }}$ than for $v_{\text {SNRT }}$ or $v_{\text {lokern }}$. Using spline, a good representation of both slow constant displacement and sudden peaks of velocities is not possible, irrespectively of the applied smoothing parameter. In contrast to spline, SNRT and lokern both adapt the size of the smoothing window to the noise in the underlying data and thus can better handle a variable SNR. An important quality of SNRT compared to the other methods is that calculated velocities always stay within the range of the data, whereas $v_{\text {lokern }}$ and especially $v_{\text {spline }}$ can over- or undershoot the true velocities. Furthermore, in contrast to the other methods tested, derived velocities with SNRT represent average velocities representative of a given period. If velocities and, thus, the SNR are high, obtained velocities have a high temporal resolution and peaks are not smoothed out. For periods with small velocities (and low SNR), the smoothing window is larger. This allows separating the signal from the noise and thus enhances the reliability of the estimated velocity and especially its variation. This is important when variations in velocity are used to investigate underlying factors and processes (cf. Coe et al., 2003; Buchli et al., 2013). Furthermore, distinguishing better between random fluctuation and real acceleration may carry benefits for early warning. A reliable assessment of SNRT in this context requires, however, more detailed investigation. The disadvantage of SNRT is that for a low SNR, a smooth acceleration of the movement (e.g. sinusoidal form) is not reproduced, but given as steps (at least for thresholds that ensure stable results). Similarly, the timing of acceleration cannot be detected exactly for a low SNR due to the large window sizes. Consequently, it is crucial when interpreting the temporal variability of $v_{\text {SNRT }}$ to note that the acceleration occurs not between the different velocity periods, but in the time between one midpoint of a period to the next midpoint. An important advantage of SNRT is that all periods have a SNR higher than the predefined threshold, which helps to interpret the temporal variability. According to Jerde and Visscher (2005) the distance between two data points should be higher than five times the error of the data in order to be able to separate the true displacement from the noise. If a threshold of $\geq 5$ is chosen with SNRT, a velocity (signal) that is at least 5 times higher than its uncertainty is obtained.

\subsection{Application to measurements}

The influence of the chosen SNR thresholds and the comparison of the different methods were further investigated with the GPS data of the pos27 and pos55 (see Sect. 5.2). While for pos 27 the median and range of the velocity estimations decrease with increasing thresholds, this is not the case for pos55 (Fig. 7). Here, the mean velocity $\left(1.6 \mathrm{~cm} \mathrm{~d}^{-1}\right)$ is about 10 times higher than the noise $(\sim 1.5 \mathrm{~mm})$. By contrast, the velocity at pos $27\left(0.45 \mathrm{~mm} \mathrm{~d}^{-1}\right)$ is less than a third of the noise $(\sim 1.5 \mathrm{~mm})$. We interpret those plots in a similar way to Laube and Purves (2011) and argue that if between the results of different thresholds no significant difference in the calculated velocities exists, the velocity estimations are no longer affected by the uncertainty in the data for those thresholds. For pos27, this means that a threshold of 15 or higher should be applied. For pos55, a threshold between 3 and 50 seems reasonable but the direction of movement becomes more stable (smaller range) when a threshold above 20 is used.

Differences between the velocities calculated with different methods were generally smaller at pos55 than at pos27 (Fig. 8), as the SNR at pos27 is lower. The temporal 
variability and range of the velocity estimations are generally the highest for the simple method. At pos27, the temporal variability of $v_{\text {lokern }}$ is clearly higher than $v_{\text {SNRT }}$ and $v_{\text {spline. }}$. At pos55 this is not so clear, especially in spring 2012 when several peaks occurred. Here, $v_{\text {simple }}$ and $v_{\text {SNRT }}$ are about 24 times higher than $v_{\text {spline }}$ or $v_{\text {lokern }}$. Furthermore, the temporal variability of $v_{\text {SNRT }}$ at pos55 was comparably high in November and December 2011. During this time the SNR was below the set threshold for various periods. This was likely caused by high standard deviations of the underlying GPS solutions (above the $95 \%$ quantile of all standard deviations). Spline and lokern fail to realistically interpolate data gaps.

\subsection{Temporal variability of estimated velocities}

Velocities at pos55 follow a seasonal cycle with the lowest values in winter (Fig. 8). In spring 2012, several peaks occurred. The strongest peak, which lasted for nearly a month, was observed in May 2012. The sinusoidal form of the seasonal velocity variations have previously been observed for rock glaciers (e.g. Haeberli, 1985; Arenson et al., 2002; Kääb et al., 2003; Perruchoud and Delaloye, 2007; Buchli et al., 2013) and is often linked to changes in air temperature (e.g. Ikeda et al., 2003; Lambiel et al., 2005; Perruchoud and Delaloye, 2007; Delaloye et al., 2010). At many rock glaciers, the highest velocities were observed between summer and early winter, and the lowest in spring or early summer (Delaloye et al., 2010). A gradual decrease in velocity in winter, phase-lagged by a few months with respect to the cooling of the ground surface, was measured at various locations (Delaloye et al., 2010). A sudden peak in velocity during the snowmelt period has also been detected on a rock glacier in the Turtmann Valley by Buchli et al. (2013). The peak occurred immediately after periods of ground-surface temperatures exceeding $0{ }^{\circ} \mathrm{C}$ and pronounced snowmelt, but nonetheless no general correlation between velocity and ground temperature was identified (Buchli et al., 2013). At pos55 not only a strong acceleration both in the horizontal and vertical directions, but also a clear change in the direction of movement occurred in May 2012. The vertical change is about $1.1 \mathrm{~m}$ higher than can be explained by the slope around the boulder $\left(34^{\circ}\right)$. We assume that during this time a second process besides rock-glacier creep was involved, potentially triggered by an increase in pore-water pressure or thawing of the ground: a rotational slide affecting the tongue of the rock glacier might have caused a sharp acceleration of the surface movement and a rotation of boulders (cf. Roer et al., 2008; Arenson, 2003). In addition, thaw consolidation might have further increased the amount of surface lowering and the rotation of the boulder (Berthling et al., 2001), however, its contribution might be minor (Brommer et al., 2012).

The velocity and its variability at pos 27 are much smaller. The duration of the velocity periods are long (several weeksmonths) because of the low SNR. However, small changes are visible: velocities were highest in autumn and lowest in midwinter. Furthermore, an acceleration was observed in spring 2012. The lowest velocities and acceleration in spring have previously been reported for landslides in the San Juan Mountains in Colorado (not in permafrost; Coe et al., 2003). After Coe et al. (2003), the availability of surface water has a stronger influence on the displacement rates than ground temperature.

\subsection{Separation of rotation and translation}

MPs are calculated both for the GPS antenna and the mast foot. While the antenna includes both the rotation and translation of the station, the foot only (or to a larger proportion) includes the translational movement. For both pos 27 and pos55, the cumulative distance at the foot is higher than at the antenna (Fig. 6). For pos55, the higher cumulative distance is caused by a mast tilt into the direction opposite to the movement $\left(\theta_{\max }=33^{\circ}\right.$ in $a z_{\max }=52^{\circ}$ and $\left.v_{a z} \approx 270^{\circ}\right)$. Here, more than $12 \%$ of the measured displacement at the antenna is caused by a rotation of the station. We assume that the rotation of the station is caused by the high movement rates, which, in combination with the high slope angle $\left(34^{\circ}\right)$, led to an unstable surface. Furthermore, a rotational slide occurring at the tongue and thaw consolidation might increase the rotation of the station (see Sect. 6.3). At pos 27 by contrast, the inclination of the mast is similar to the direction of movement and thus a higher displacement at the antenna would be expected but nearly no tilt of the mast occurs $\left(\theta_{\max }=1.4^{\circ}, a z_{\max }=117^{\circ}\right.$, Fig. 2). Moreover, at pos 27 the uncertainty of the inclinometer measurements is high $\left(\sigma_{\theta}=1.1^{\circ}\right.$ and $\left.\sigma_{a z}=101^{\circ}\right)$ and thus SNR is low. As a consequence, the signal in the rotation measurements cannot be separated from its uncertainty, which leads to incorrect estimations of the rotation.

At pos55, the displacement of the foot is more linear compared to the antenna (Fig. 9). This is not the case at pos27. Here, differences between the displacement at the antenna and the foot are highest after device changes, but generally small. After each device change, the differing sensors have slightly different readings which results in changes in the tilt that are larger than the actual rotation of the mast itself at pos27. For pos55, this effect is less important because of the comparably larger tilt and displacement.

The influence of the assumption that the GPS foot is the centre of rotation increases with an increase in size of the boulder on which the GPS station is mounted. A more realistic centre of rotation can be approximated by applying different values of the mast height $\left(1.5 \mathrm{~m}<h_{\text {mast }}<3.5 \mathrm{~m}\right)$. At the most realistic centre of rotation, the direction of movement should be the smoothest. For pos55, we estimated that the centre of rotation lies approximately $2.5 \mathrm{~m}$ below the antenna, i.e. about $1 \mathrm{~m}$ within the boulder. This seems reasonable as the boulder has a diameter on the order of $2 \mathrm{~m}$ (Fig. 1). 


\section{Conclusions and outlook}

The developed method (SNRT) adaptively calculates a smoothing window based on the SNR of the position data. The SNR is estimated using Monte Carlo simulations. Derived velocities represent average velocities representative of a given period. Each velocity period has a known SNR that is above a predefined threshold. This helps to understand the influence of the uncertainty of the data and to interpret the temporal variability.

Sensitivity tests with synthetic time series revealed that for position data with high noise levels, estimated velocities strongly depend on the chosen method and parameter settings, especially if the SNR is variable. For high noise levels a smoothing of the data is crucial to obtain realistic velocity estimations. Furthermore, for variable SNRs, the performance of methods that adapt the smoothing window to the noise of the data is clearly better. SNRT has proven to be a suitable method to obtain reliable velocity estimations based on noisy GPS data with variable SNR.

SNRT allows us to empirically select a suitable threshold on the basis of the SNR estimated through MCS. In our case study we found that for a threshold of 15 or higher, velocity estimations were no longer affected by the uncertainty in the data.

With the application to a case study, we could show that based on SNRT the temporal variability of permafrost slope movements can be investigated. The GPS station on the rock glacier (pos55) followed a seasonal cycle with lowest velocities in midwinter. During snowmelt several peaks occurred. At pos27, located on a deep-seated landslide, the seasonal signal is less clear. Velocities tend to be highest in autumn and lowest in midwinter.
This study showed that error related to the rotation of the GPS station depends on the tilt of the mast and its uncertainty. If the rotation is higher than its uncertainty, the rotational movement can be separated and the direction of movement of the mast foot (corrected for the mast tilt) became more stable compared to the antenna. If the rotation of the station is small and stays within the uncertainty of the measurements, the correction of the mast tilt leads to lowerquality results.

Performance tests revealed that SNRT is a suitable method for detecting changes in velocity, even for position data with a high noise level and variable SNR. According to our analysis, the SNRT method is better suited for the analysis of movements with small changes in velocities compared to their noise level (e.g. deep-seated landslides) than common methods such as spline or lokern. The SNRT method can be used to analyse position data that include both periods of slow continuous displacement and short periods of high velocities (e.g. sudden acceleration of rock glaciers or slopes with gelifluction during the (snow-)melt period in spring). However, if the noise level is high then detection of the exact timing of acceleration is difficult (as is the case for all of the methods tested). Furthermore, additional tests on real movement patterns would help to further investigate the performance of SNRT. 


\section{Appendix A}

To calculate the inclination $(\theta)$ an its azimuth $(\phi)$ in the local coordinate system, the rotation of the mast is decomposed into three components (cf. Corripio, 2003): one around the $z$ axis by the azimuth, a second around the $x$ axis by the inclination and a third back around the $z$ axis by the negative azimuth. The vector of the mast in the rotated reference system can then be described as the original vector multiplied by the three rotational matrices:

$$
\begin{aligned}
& \theta=\operatorname{acos}\left(\sqrt{\cos (X)^{2}+\cos (Y)^{2}-1}\right), \\
& \phi=\frac{0.5 \times \operatorname{acos}\left(\cos (X)^{2}-\cos (Y)^{2}\right)}{\cos (X)^{2}+\cos (Y)^{2}-2},
\end{aligned}
$$

with the inclination in the $x$ direction $(X)$ and the inclination in the $y$ direction $(Y)$. 


\section{Appendix B}

In Appendix B, the selection of the smoothing window within the SNRT method is described with more detail based on a Figure (Fig. B1) and pseudocode (Fig. B2): the applied smoothing window directly depends on the SNR of the position data. For each velocity period the SNR of the velocity must be higher than a predefined $t$. The uncertainty of the velocity is estimated with MCS. In each simulation, an error is assigned to the positions and the velocity (linear regression) is calculated. It is looped through all available connected data points (chunks) with an increasing size of the smoothing window and tested if the SNR of the velocity is higher than $t$. If the criterium is fulfilled, a velocity is assigned to those data points and they are excluded in further processing (i.e. no longer available).
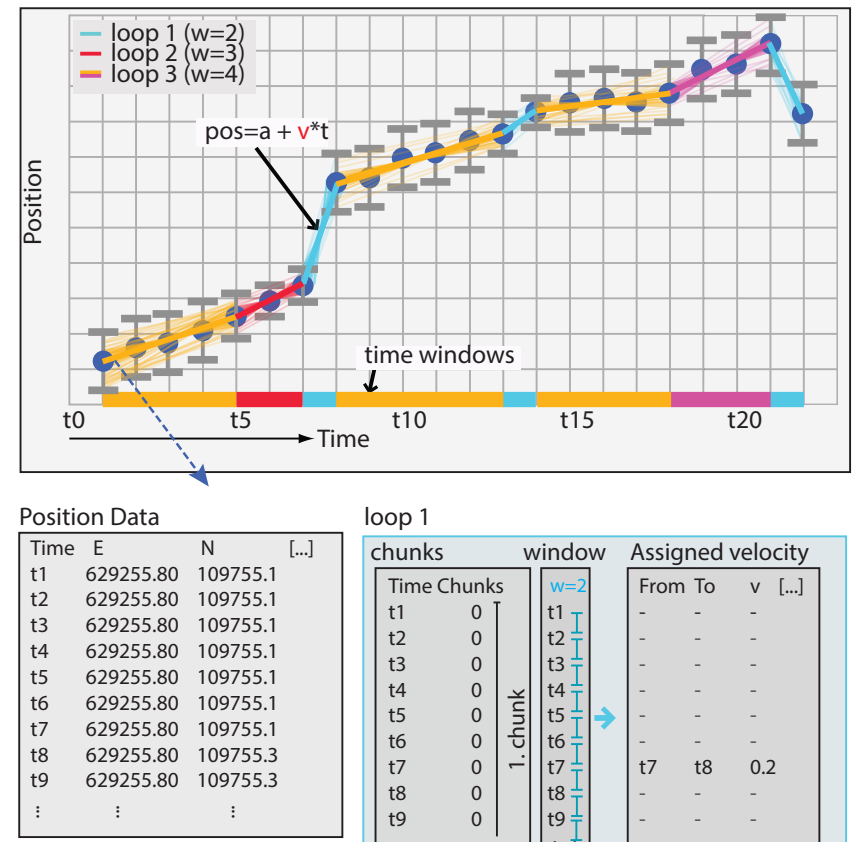

loop 1
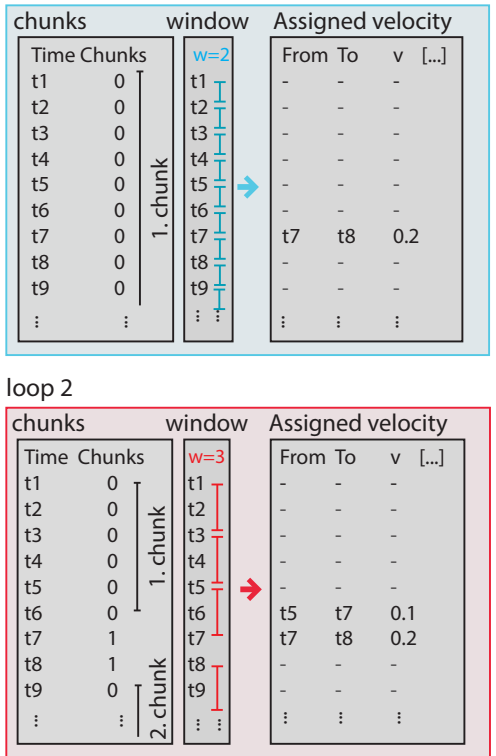

Figure B1. Schematic depiction of the algorithm. Based on positions and their standard deviations, velocities are estimated with linear regressions. The time window (number of measurements) applied depends on the signal to noise component. If the SNR is higher than the predefined threshold (the SNR criterion is fulfilled), a velocity is assigned to the period. We loop through all chunks (available connected data points) while increasing the size of the smoothing window $(w)$ until to each data point a velocity is assigned. See text and pseudocode for more detail. 
Data: Matrix of positions with: timestamp, E+uncertainty, $\mathrm{N}+$ uncertainty, $\mathrm{h}+$ uncertainty

Result: Matrix of estimated MPs with: time period (from, to), $\mu_{v}, a z i_{v}$, $\sigma_{v}, \sigma_{a z i-v}, \mathrm{SNR}$ /* Start with the smallest window size (2) and end
with maximal window size (n=number of data
points)

for $w \leftarrow 2$ to $n$ do

get chunks: chunks of available connected data points;

/* Get chunks of available (no MPs assigned so

far) connected data points */

for this.chunk in chunks do
$\quad / *$ Loop through all the individual chunks

* /

if length(this.chunks) $<2 * w$ then

I* Cannot further split this.chunk, therefore a mean velocity over all

data points of this.chunk is calculated.

calculate MP and SNR / * MCS are used to estimate the uncertainty of MPs, see sec. $4.1 .2 \quad * /$ save MP;

mask data points of this.chunk / * Data points within this.chunk are masked and to exclude from further processing. */

next /* jump to next this.chunk */ end for row.beg $\leftarrow($ beg $-w+1)$ to (chunk.end $-w-1)$ do

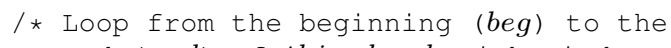

end

Figure B2. Pseudocode to describe the selection of smoothing-windows in SNRT, with size of smoothing widow $w$, total number of data points $n$, chunks of available connected data points of the trajectory. The algorithm, including position data, chunks and smoothing window are illustrated in Fig. B1. 
Acknowledgements. This project was funded through nano-tera.ch, project X-Sense. This work was also supported by the Grid Computing Competence Center (GC3, www.gc3.uzh.ch) with computational infrastructure and support, including customized libraries (gc_gps and GC3Pie) and user support. P. Limpach (Geodesy and Geodynamics Lab of ETH Zurich) is thanked for the processing of the daily GPS solutions. This study would not have been possible without the collaboration with colleagues from the project X-Sense, especially Ben Buchli and Tonio Gsell (both from Computer Engineering and Networks Lab of ETH Zurich).

Edited by: R. Lasaponara

Reviewed by: I. Berthling and one anonymous referee

\section{References}

Arenson, L., Hoelzle, M., and Springman, S.: Borehole deformation measurements and internal structure of some rock glaciers in Switzerland, Permafrost Periglac., 13, 117-135, 2002.

Arenson, L.: Unstable alpine permafrost: a potentially important natural hazard - variations of geotechnical behaviour with time and temperature, $\mathrm{Ph} . \mathrm{D}$. thesis, Institut for geotechnical engeneering, ETH Zuerich, 2003.

Berthling, I., Eiken, T., Madsen, H., and Sollid, J.: Continuous measurements of solifluction using carrier-phase differential GPS, Norweg. J. Geogr., 54, 182-185, 2000.

Berthling, I., Eiken, T., Madsen, H., and Sollid, J.: Downslope displacement rates of ploughing boulders in a mid-alpine environment: Finse, southern Norway, Geograf. Ann. Ser. A, 83, 103116, 2001.

Beutel, J., Buchli, B., Ferrari, F., Keller, M., Thiele, L., and Zimmerling, M.: X-sense: sensing in extreme environments, in: Proceedings of design, automation and test in Europe, 2011, IEEE, $1-6,2011$.

Boeckli, L., Brenning, A., Gruber, S., and Noetzli, J.: Permafrost distribution in the European Alps: calculation and evaluation of an index map and summary statistics, The Cryosphere, 6, 807820, doi:10.5194/tc-6-807-2012, 2012.

Brommer, C., Fitze, P. and Schneider, H., Permafr. Perigl. Proc., 23, 1099-1530, 2012.

Buchli, B., Sutton, F., and Beutel, J.: GPS-equipped wireless sensor network node for high-accuracy positioning applications, in: Wireless Sensor Networks, Springer, 179-195, 2012.

Buchli, T., Merz, K., Zhou, X., Kinzelbach, W., and Springman, S.: Characterization and monitoring of the Furggwanghorn rock glacier, Turtmann Valley, Switzerland: results from 2010 to 2012, Vadose Zone J., 12, 1-15, 2013.

Chambers, J. and Hastie, T.: Statistical Models in S, Chapman \& Hall, London, 1992.

Coe, J., Ellis, W., Godt, J., Savage, W., Savage, J., Michael, J., Kibler, J., Powers, P., Lidke, D., and Debray, S.: Seasonal movement of the Slumgullion landslide determined from Global Positioning System surveys and field instrumentation, Eng. Geol., 68, 67-101, 2003.

Copland, L., Sharp, M., and Nienow, P.: Links between short-term velocity variations and the subglacial hydrology of a predominantly cold polythermal glacier, J. Glaciol., 49, 337-348, 2003.
Corripio, J.: Vectorial algebra algorithms for calculating terrain parameters from DEMs and solar radiation modelling in mountainous terrain, Int. J. Geogr. Inf. Sci., 17, 1-23, 2003.

Crosta, G. and Agliardi, F.: How to obtain alert velocity thresholds for large rockslides, Phys. Chem. Earth, 27, 1557-1565, 2002.

Crosta, G. and Agliardi, F.: Failure forecast for large rock slides by surface displacement measurements, Can. Geotech. J., 40, 176191, 2003.

Dach, R., Hugentobler, U., Fridez, P., and Meindl, M.: Bernese GPS Software, Version 5.0. Astronomical Institute, University of Bern, 2007.

Delaloye, R., Kaufmann, M., Bodin, X., Hausmann, H., Ikeda, A., Kääb, A., Kellerer-Pirklbauer, A., Krainer, K., Lambiel, C., Mihajlovic, D., Roer, I., and Thibert, E.: Recent interannual variations of rock glacier creep in the European Alps, in: Proceedings of the 9th International Conference on Permafrost, Fairbanks, Alaska, 343-348, 2008a.

Delaloye, R., Strozzi, T., Lambiel, C., Perruchoud, E., and Raetzo, H.: Landslide-like development of rockglaciers detected with ERS-1/2 SAR interferometry, in: Proceedings of the 8th International Conference on Permafrost, Zürich, Switzerland, 2630, 2008b.

Delaloye, R., Lambiel, C., and Gärtner-Roer, I.: Overview of rock glacier kinematics research in the Swiss Alps, Geogr. Helv., 65, 135-145, doi:10.5194/gh-65-135-2010, 2010.

Delaloye, R., Barboux, C., Morard, S., Abbet, D., and Gruber, V.: Rapidly moving rock glaciers in Mattertal, in: Mattertal - ein Tal in Bewegung, edited by: Graf, C., Publikation zur Jahrestagung der Schweizerischen Geomorphologischen Gesellschaft, 29 June-1 July 2011, St. Niklaus, 21-31, 2013.

den Ouden, M. A. G., Reijmer, C. H., Pohjola, V., van de Wal, R. S. W., Oerlemans, J., and Boot, W.: Standalone single-frequency GPS ice velocity observations on Nordenskiöldbreen, Svalbard, The Cryosphere, 4, 593-604, doi:10.5194/tc-4-593-2010, 2010.

Dunse, T., Schuler, T. V., Hagen, J. O., and Reijmer, C. H.: Seasonal speed-up of two outlet glaciers of Austfonna, Svalbard, inferred from continuous GPS measurements, The Cryosphere, 6, 453466, doi:10.5194/tc-6-453-2012, 2012.

Gasser, T., Kneip, A., and Köhler, W.: A flexible and fast method for automatic smoothing, J. Am. Stat. Assoc., 86, 643-652, 1991.

Gili, J., Corominas, J., and Rius, J.: Using Global Positioning System techniques in landslide monitoring, Eng. Geol., 55, 167-192, 2000.

Haeberli, W.: Creep of mountain permafrost: internal structure and flow of alpine rock glaciers, Mitteilungen der Versuchsanstalt fur Wasserbau, Hydrologie und Glaziologie an der ETH Zurich, 77, 5-142, 1985.

Haeberli, W., Wegmann, M., and Vonder Mühll, D.: Slope stability problems related to glacier shrinkage and permafrost degradation in the alps, Eclogae Geol. Helv., 90, 407-414, 1997.

Hanson, B. and Hooke, R.: Short-term velocity variations and basal coupling near a bergschrund, Storglaciaren, Sweden, J. Glaciol., 40, 67-74, 1994.

Hastie, T. and Tibshirani, R.: Generalized additive models, Stat. Sci., 1, 297-310, 1986.

Herrmann, E.: Local bandwidth choice in kernel regression estimation, J. Comput. Graph. Stat., 6, 35-54, 1997. 
Ikeda, A., Matsuoka, N., and Kääb, A.: A rapidly moving small rock glacier at the lower limit of the mountain permafrost belt in the Swiss Alps, in: Proceedings of the 8th International Conference on Permafrost, Zürich, Switzerland, 1, 455-460, 2003.

Jerde, C. and Visscher, D.: GPS measurement error influences on movement model parameterization, Ecol. Appl., 15, 806-810, 2005.

Kääb, A., Kaufmann, V., Ladstädter, R., and Eiken, T.: Rock glacier dynamics: implications from high-resolution measurements of surface velocity fields, in: Proceedings of the 8th International Conference on Permafrost, Zürich, Switzerland, 501-506, 2003.

Labhart, T.: Geologie der Schweiz, 3rd edn., Thun Ott, 1995.

Lambiel, C. and Delaloye, R.: Contribution of real-time kinematic GPS in the study of creeping mountain permafrost: examples from the Western Swiss Alps, Permafrost Periglac., 15, 229-241, 2004.

Lambiel, C., Delaloye, R., and Perruchoud, E.: Yearly and seasonally variations of surface velocities on creeping permafrost bodies. Cases studies in the Valais Alps, in: 3rd Swiss Geoscience Meeting, Zürich, 1-2, 2005.

Laube, P. and Purves, R. S.: How fast is a cow? Cross-scale analysis of movement data, Transactions in GIS, 15, 401-418, 2011.

Lewkowicz, A. and Harris, C.: Frequency and magnitude of activelayer detachment failures in discontinuous and continuous permafrost, northern Canada, Permafrost Periglac., 16, 115-130, 2005.

Li, L.: Separablity of deformations and measurement noises of gps time series with modified kalman filter for landslide monitoring in real-time, Ph.D. thesis, Universitäts- und Landesbibliothek Bonn, 2011.

Limpach, P. and Grimm, D.: Rock glacier monitoring with lowcost GPS receivers, in: 7th Swiss Geoscience Meeting, November 2009, Neuchatel, Switzerland, 247-248, 2009.

Mair, D., Nienow, P., Willis, I., and Sharp, M.: Spatial patterns of glacier motion during a high-velocity event: Haut Glacier d'Arolla, Switzerland, J. Glaciol., 47, 9-20, 2001.

Malet, J., Maquaire, O., and Calais, E.: The use of Global Positioning System techniques for the continuous monitoring of landslides: application to the Super-Sauze earthflow (Alpes-deHaute-Provence, France), Geomorphology, 43, 33-54, 2002.

Massey, C., Petley, D., and McSaveney, M.: Patterns of movement in reactivated landslides, Eng. Geol., 159, 1-19, 2013.
Perruchoud, E. and Delaloye, R.: Short-term changes in surface velocities on the Becs-de-Bosson rock glacier (western Swiss Alps), Grazer Schriften der Geographie und Raumforschung, 43, 131-136, 2007.

Roer, I., Haeberli, W., Avian, M., Kaufmann, V., Delaloye, R., Lambiel, C., and Kääb, A.: Observations and considerations on destabilizing active rock glaciers in the European Alps, in: Proceedings of the 9th International Conference on Permafrost, Fairbanks, Alaska, 2, 1505-1510, 2008.

Schleppe, J. and Lachapelle, G.: Tracking performance of a HSGPS receiver under avalanche deposited snow, GPS Solutions, 12, 1321, 2008.

Seifert, B., Brockmann, M., Engel, J., and Gasser, T.: Fast algorithms for nonparametric curve estimation, J. Comput. Graph. Stat., 3, 192-213, 1994.

Squarzoni, C., Delacourt, C., and Allemand, P.: Differential singlefrequency GPS monitoring of the La Valette landslide (French Alps), Eng. Geol., 79, 215-229, 2005.

Strozzi, T., Wegmuller, U., Werner, C., Wiesmann, A., Delaloye, R., and Raetzo, H.: Survey of landslide activity and rockglaciers movement in the Swiss Alps with TerraSAR-X, in: Geoscience and Remote Sensing Symposium, 2009 IEEE International, IGARSS, 12-17 July 2009, 3, III-53-III-56, 2009.

Varnes, D.: Slope Movement Types and Processes, Transportation Research Board Special Report 176, Landslides: Analysis and Control, 1978.

Vieli, A., Jania, J., Blatter, H., and Funk, M.: Short-term velocity variations on Hansbreen, a tidewater glacier in Spitsbergen, J. Glaciol., 50, 389-398, 2004.

VTI Technologies: Sca830-d07: 1-axis inclinometer with digital SPI interface, Data-sheet, Doc. nr. $8282300 \mathrm{C}$, available at: www.vti.fi, 2010.

Wirz, V., Limpach, P., Buchli, B., Beutel, J., and Gruber, S.: Temporal characteristics of different cryosphere-related slope movements in high mountains, in: Landslide Science and Practice, edited by: Margottini, C., Canuti, P., and Sassa, K., Springer, Berlin, Heidelberg, 383-390, 2013.

Yin, Y., Wang, H., Gao, Y., and Li, X.: Real-time monitoring and early warning of landslides at relocated Wushan Town, the Three Gorges Reservoir, China, Landslides, 7, 339-349, 2010. 